\title{
Undergraduate Students’ Attitudes toward Biodiversity
}

\author{
Hui-Ju Huang ${ }^{1, *}$,Yu-Teh Kirk Lin ${ }^{2}$ \\ ${ }^{1}$ Department of Teacher Education, California State University Sacramento, 6000 J Street, Sacramento, CA 95819 \\ ${ }^{2}$ Department of Life Science, National Taiwan University, No. 1, Sec. 4, Roosevelt Road, Taipei, 10617 Taiwan
}

Copyright (C) 2014 Horizon Research Publishing All rights reserved.

\begin{abstract}
The study investigated American and Taiwan undergraduate students' attitudes toward biodiversity. The survey questionnaire consisted of statements prompted by the question "To what extent do you agree with the following statements about problems with the biodiversity issues." Students indicated strongly disagree, disagree, agree, strongly agree, or no opinion. The questionnaire inquired students' awareness of biodiversity and the impact of human activity on biodiversity. The students' attitudes were analyzed by frequency of response and average value of response. The t-test was conducted to examine the difference among students of different backgrounds. The results showed that both American and Taiwan undergraduate students had consensus that they expressed lower level of confidence in the ability of science and technology to solve biodiversity problems, and they did not agree that people worry too much about the problem of biodiversity issue. There were also significant differences between different groups (gender, with or without experience of conservation activities). Understanding students' attitudes is important for educators to plan curriculum and instruction.
\end{abstract}

Keywords Biodiversity, Environmental Education, Student Voice, International Study

\section{Introduction}

The protection of biodiversity has been identified as one of the major pathways to sustainability [1].Biodiversity is defined as "the variability among living organisms from all sources including, inter alia, terrestrial, marine and other aquatic ecosystem and the ecological complexes of which they are part: this includes diversity within species, between species and of ecosystems" [2]. Biodiversity is an important issue with broad ramifications for the quality of human life and it is relative to the impact on agriculture, public health, ecological balance, and climate change [3].The accelerating decline in biodiversity because of human activities is one of the most urgent environmental issues $[4,5]$. To safeguard the richness of life forms, it is essential to raise public awareness about the need to preserve biodiversity [6, 7].

In recent years biodiversity has become an important focus of scientific research and political discussion [8]. It is also a relatively new issue in educational research and formal education [9]. To promote biodiversity education, students' preconceptions, interest, and attitude need to be taken into account in the construction of curriculum $[10,11]$.The purpose of the study is to investigate undergraduate students' attitudes toward biodiversity. Specifically, the research questions are:

1. What are undergraduate students' overall attitudes toward biodiversity?

2. What are differences of attitude toward biodiversity among students of different background (i.e. gender, resident country, with and without experience of conservation activities, local v.s. global issues)?

\section{Literature Review}

The study is rooted in the socio-constructivism framework and views learning as a social construction among cognitively and emotionally active individuals interacting with physical world [12, 13].Traditionally, research on science learning has centered on memory, thought, and reasoning [14]. Similarly, most research about biodiversity is generally focused on educational program and students' knowledge about biodiversity [15]. Hicks and Bord [16] criticize that teachers in elementary, secondary and university tend to focus on cognitive structural strategies and ignore affective dimension of the learning process in environmental education, which will lead to the level of anxiety increase, thus, restrict learning. There is a need to build connections between cognitive and affective dimensions of student learning [17].Affective dimension is the fuel that students bring to the classroom, connecting them to the why of learning. It contributes to students' feelings of pleasure and confidence or inadequacy, frustration or even alienation from the science experience. The more that is known about students' interests, enthusiasm, beliefs, and attitudes, the more feasible it will be to develop curricula or programs of biodiversity education that will engage students' attention and empower otherwise silent voices in the many 
debates surrounding biodiversity issues and concerns.

The study is also based on the environmental literacy framework[18]. Environmental literacy refers to an individual's knowledge about and attitudes toward the environment and environmental issues; skills and motivation to work toward the resolution of environmental problems and active involvement in working towards the maintenance of dynamic equilibrium between the quality of life and quality of environment. Biodiversity is renewing the discourse on environmental issues by bringing together different groups in society to discuss the issues in relation to sustainability[19]. Throughout official documents dealing with the problems of biodiversity reduction, it has been repeatedly affirmed that participation of all citizens is essential if the situation is to be improved[20].

\section{Research Methodology}

To investigate undergraduate students' attitudes toward biodiversity, the survey questionnaire consisted of ten statements prompted by the question "To what extent do you agree with the following statements about problems with the biodiversity issues." Students indicated their degree of agreement including, strongly disagree, disagree, agree, strongly agree, and no opinion. The questionnaire statements were inspired by Jenkins \& Pell's [21] study of students' attitude towards environmental issues. The researchers modified the statements so that they focused on biodiversity, instead of general environmental issues. The validity and reliability of the questionnaire were triangulated with findings from a previous stage of the overall research project. The questionnaire mainly inquired students' awareness of biodiversity and the impact of human activity on biodiversity. In addition, the survey of students' attitudes toward local and global issues was to present statements with a specific context. The local issue is about the lost of biodiversity due to business development and the global issue is about the lost of biodiversity due to exploitation of rainforest. Students were asked to select to what extent they cared about the issues from 1-10 scale as 1 the lowest and 10 the highest.

American and Taiwan undergraduate students participated in the study by filling out the survey questionnaire anonymously. A total of 108 surveys were collected from American students. Among 108 students, 21 are males, 87 are females, and 32 students self-reported that they had experience of conservation works such as member of association of environmental and outdoor education, and volunteer for habitat restoration and recycle program. The questionnaire given to Taiwan students was translated into Chinese, and a total of 126 surveys were collected. Of the 126 students, 64 are males, 62 are females and 14 self-reported that they had experience of conservation works such as volunteer for habitat restoration, recycle program, and earth day program. Both groups of students' background include a range of subject area majors such as liberal arts, education, science, engineer, and businesses.

The overall students' attitudes were analyzed by calculating frequency of response regarding four levels (strongly disagree, disagree, strongly agree, and agree) and no opinion. The degree of agreement with the survey statements was assigned numerical values: strongly disagree $=1$, disagree $=2$, agree $=3$, strongly agree $=4$, and no opinion $=0$. We analyzed the average value of response (mean and standard error), and the samples of no opinion were excluded when calculating it. Thet-test was also conducted to examine the difference of attitude toward biodiversity among students of different background (Taiwan students and American students, male and females; with or without experiences of conservation activities), as well as the attitude toward local and global issues.

\section{Results}

\subsection{Overall Attitudes toward Biodiversity}

The statistics summarizing overall responses shows that American students' average response value to the questionnaire statements is in the range from 1.76 \pm 0.08 to $3.08 \pm 0.10$ (Table 1 ). On the other hand, Taiwan students' average response value is in the range from $2.19 \pm 0.08$ to 2.72 \pm 0.07 (Table 1).

Most American students had similar response pattern that more than $50 \%$ of students would either agree or disagree with the statement (table 2). There were two statements (5 \& 7) that students' attitude were more evenly distributed between both sides. A range of $6-14 \%$ students chose "no opinions" on different statements.

Taiwan students had similar response pattern that the majority would either agree or disagree with the statement(table 3$)$. There were two statements ( 2 \&8) that Taiwan students' attitudes were more evenly distributed between both sides. A range of 2-6 \% of students chose "no opinions.” 
Table 1. Average response values by American and Taiwan students.

\begin{tabular}{|c|c|c|c|}
\hline Statement & $\begin{array}{c}\text { U.S (Average } \\
\text { response values, Mean } \pm \text { 1SE) }\end{array}$ & $\begin{array}{c}\text { Taiwan (Average } \\
\text { response values, Mean } \pm \text { 1SE) }\end{array}$ & P value \\
\hline$* 1$ & $1.76 \pm 0.08$ & $2.30 \pm 0.07$ & $<0.0001$ \\
\hline$* 2$ & $1.94 \pm 0.07$ & $2.56 \pm 0.08$ & 0.0002 \\
\hline$* 3$ & $1.79 \pm 0.08$ & $2.19 \pm 0.08$ & $<0.0001$ \\
\hline$* 4$ & $3.08 \pm 0.10$ & $2.45 \pm 0.08$ & 0.016 \\
\hline$* 5$ & $2.49 \pm 0.09$ & $2.21 \pm 0.08$ & 0.857 \\
\hline 6 & $2.31 \pm 0.09$ & $2.29 \pm 0.08$ & 0.018 \\
\hline$* 7$ & $2.46 \pm 0.08$ & $2.72 \pm 0.07$ & 0.007 \\
\hline$* 8$ & $2.75 \pm 0.09$ & $2.44 \pm 0.08$ & $<0.0001$ \\
\hline 10 & $1.87 \pm 0.07$ & $2.64 \pm 0.07$ & 0.346 \\
\hline
\end{tabular}

Note: P-values give the results of t-tests. Significance level $\mathrm{p}<0.05$.

Note: * by the statement numbers denote that the responses by the two groups are significantly different.

Table 2. American students' attitudes towards biodiversity by frequency of response ( $\mathrm{N}=108)$

\begin{tabular}{|c|c|c|c|c|c|c|c|}
\hline Statement & $\begin{array}{c}\text { Strongly } \\
\text { disagree }\end{array}$ & Disagree & SD + D & Agree & Strongly agree & A+SA & No opinion \\
\hline 1 & $40 \%$ & $33 \%$ & $73 \%$ & $13 \%$ & $3 \%$ & $16 \%$ & $11 \%$ \\
\hline 2 & $25 \%$ & $51 \%$ & $76 \%$ & $16 \%$ & $2 \%$ & $18 \%$ & $6 \%$ \\
\hline 3 & $35 \%$ & $40 \%$ & $75 \%$ & $11 \%$ & $3 \%$ & $14 \%$ & $11 \%$ \\
\hline 4 & $7 \%$ & $17 \%$ & $24 \%$ & $31 \%$ & $39 \%$ & $70 \%$ & $6 \%$ \\
\hline 5 & $14 \%$ & $29 \%$ & $43 \%$ & $36 \%$ & $11 \%$ & $47 \%$ & $10 \%$ \\
\hline 6 & $14 \%$ & $48 \%$ & $62 \%$ & $19 \%$ & $12 \%$ & $31 \%$ & $7 \%$ \\
\hline 7 & $9 \%$ & $36 \%$ & $45 \%$ & $32 \%$ & $8 \%$ & $40 \%$ & $14 \%$ \\
\hline 8 & $4 \%$ & $38 \%$ & $42 \%$ & $30 \%$ & $22 \%$ & $52 \%$ & $6 \%$ \\
\hline 9 & $26 \%$ & $51 \%$ & $77 \%$ & $12 \%$ & $1 \%$ & $2 \%$ & $10 \%$ \\
\hline 10 & $23 \%$ & $40 \%$ & $63 \%$ & $21 \%$ & $6 \%$ & $27 \%$ & $10 \%$ \\
\hline
\end{tabular}

Table 3. Taiwan students' attitudes towards biodiversity by frequency of response $(\mathrm{N}=126)$

\begin{tabular}{|c|c|c|c|c|c|c|c|}
\hline Statement & $\begin{array}{c}\text { Strongly } \\
\text { disagre }\end{array}$ & Disagree & SD + D & Agree & Strongly agree & A+SA & No opinion \\
\hline 1 & $11 \%$ & $51 \%$ & $62 \%$ & $33 \%$ & $4 \%$ & $37 \%$ & $2 \%$ \\
\hline 2 & $7 \%$ & $46 \%$ & $53 \%$ & $31 \%$ & $16 \%$ & $47 \%$ & $0 \%$ \\
\hline 3 & $17 \%$ & $53 \%$ & $70 \%$ & $21 \%$ & $7 \%$ & $28 \%$ & $2 \%$ \\
\hline 4 & $8 \%$ & $48 \%$ & $56 \%$ & $29 \%$ & $11 \%$ & $40 \%$ & $4 \%$ \\
\hline 5 & $18 \%$ & $46 \%$ & $64 \%$ & $25 \%$ & $6 \%$ & $31 \%$ & $4 \%$ \\
\hline 6 & $13 \%$ & $52 \%$ & $65 \%$ & $23 \%$ & $9 \%$ & $32 \%$ & $4 \%$ \\
\hline 7 & $5 \%$ & $28 \%$ & $33 \%$ & $50 \%$ & $11 \%$ & $61 \%$ & $6 \%$ \\
\hline 8 & $11 \%$ & $40 \%$ & $51 \%$ & $37 \%$ & $9 \%$ & $46 \%$ & $3 \%$ \\
\hline 9 & $3 \%$ & $35 \%$ & $38 \%$ & $48 \%$ & $7 \%$ & $55 \%$ & $6 \%$ \\
\hline 10 & $17 \%$ & $44 \%$ & $61 \%$ & $26 \%$ & $6 \%$ & $32 \%$ & $6 \%$ \\
\hline
\end{tabular}




\subsection{Comparison of Attitude between Different Groups}

The results of t-test show that there were significant differences between American and Taiwan students' attitudes on eight statements except $6 \& 10$ (Table 1). The responses to these two statements showed that the majority of both group expressed lower level of confidence in the ability of science and technology to solve biodiversity problems(statements 6 ) and they disagreed that people worry too much about the problem of biodiversity issues (statements 10). With regard to the other survey questions, American students tended to have strong attitude comparing to Taiwan students. More than 25\% of American students chose "strongly disagree" or "strongly agree", but less than 25\% Taiwan students would do so (table $2 \& 3$ ).

American and Taiwan students had opposite response pattern towards statements $4 \& 9$. With regard to the statement 4 (I think each of us can make a significant contribution to solve problems of biodiversity issues), a majority of American students (70\%) agreed or strongly agreed with this statement(table 2). On the contrary, less than half of Taiwan students (40\%) agreed or strongly agreed (table 3). Although high percentage of American students agreed that they could make a significant contribution to solve biodiversity problems, such agreement was not reflected in a corresponding willingness to "have problems of biodiversity issues solved even if this meant sacrificing many goods" (statement 5) as less than half students (43\%) agreed with this statement (table 2).

Another opposite response pattern of two groups was students' attitude toward the exploitation of biodiversity for basic human needs(statement 9). More American students
(77\%) selected "strongly disagree/disagree" than "strongly agree/agree"(13\%)(table 2). Although more Taiwan students (55\%) selected agree than disagree (38\%) with this statement (table 3), most of them did not agree with the exploitation of biodiversity for economic growth when responding to the statement 3 (The demand for economic growth is critical enough to justifying relaxing some of the environmental restrictions relating to biodiversity issues).

It is noted that there was less support among American students (18\%) for the view that biodiversity issues be left to the experts (statement 2), whereas Taiwan students' attitudes were distributed between both sides (53\% agree and $47 \%$ agree). Another notable result is regarding the statement 7 (The natural world is sacred and should be left in peace). American students had the highest number (14\%) of "no opinion", and their attitudes were evenly distributed (9\% strongly disagree, $36 \%$ disagree, $8 \%$ strongly agree, and $32 \%$ agree). There was, however, a majority support among Taiwan students (61\%) for the notion of the natural world as something sacred that should be left in peace.

More comparison between different groups is shown in Table 4.Asignificant difference between Taiwan male and females was on the statement1 (The goal of conserving biodiversity is a threat to the continued economic prosperity of our country). More Taiwan females than males selected "strongly disagree/disagree" with the statement. Similarly, more American females than males did not agree with this statement. Another significance difference among American males and females was that more females than males disagreed with the statement 8 (Nearly all human activities cause the loss of biodiversity) (table 4).

Table 4. Comparison of attitude between different groups

\begin{tabular}{|c|c|c|c|c|}
\hline Statement & $\begin{array}{c}\text { U.S. Male/Female } \\
\text { (Average } \\
\text { Response Values, } \\
\text { Mean } \pm \text { SSE) }\end{array}$ & $\begin{array}{c}\text { Taiwan Male/Female } \\
\text { (A.R.V.) } \\
1.61 \pm 0.08\end{array}$ & $\begin{array}{c}\text { U.S. students w/without } \\
\text { conservation experience } \\
\text { (A.R.V.) }\end{array}$ & $\begin{array}{c}\text { Taiwan students } \\
\text { w/without } \\
\text { conservation } \\
\text { experience }\end{array}$ \\
\hline 1 & $\begin{array}{c}* 29 \pm 0.24 \text { v.s. } \\
\text { (NSD) }\end{array}$ & NSD v.s. $2.15 \pm 0.09$ & $* 1.53 \pm 0.13$ v.s. $1.88 \pm 0.10$ & NSD \\
\hline 2 & NSD & NSD & $* 1.55 \pm 0.11$ v.s. $1.91 \pm 0.10$ & $\begin{array}{c}3.00 \pm 0.18 \text { v.s. } \\
2.5 \pm 0.08\end{array}$ \\
\hline 3 & NSD & NSD & $* 3.39 \pm 0.16$ v.s. $2.94 \pm 0.11$ & NSD \\
\hline 4 & NSD & NSD & NSD & NSD \\
\hline 5 & NSD & NSD & NSD & NSD \\
\hline 6 & NSD & NSD & NSD & NSD \\
\hline 7 & $* 3.14 \pm 0.19$ v.s. $2.65 \pm 0.09$ & NSD & NSD & NSD \\
\hline 9 & NSD & NSD & $* 1.72 \pm 0.13$ v.s. $2.26 \pm 0.11$ & NSD \\
\hline
\end{tabular}

Note: P-values give the results of t-tests. Significance level $\mathrm{p}<0.05$

Note: * by the Average response values denote that the responses by the two groups are significantly different.

NSD: No significant difference

American students with experience of conservation work expressed stronger attitude than non-experience group (table 
4). They strongly disagree with four statements $(1,2,3,10)$, and they all agreed that they could make a significant contribution to solve problems of biodiversity issues. Among Taiwan students, there was only one significant difference between the two groups (experience of conservation works or not) on the statement 2 (Problems of biodiversity issues should be left to the experts). More students of experience group agreed with this statement than those without experience. This was also the only statement that none of Taiwan students selected "no opinion."

With regard to the local and global issues, seven American students left this item blank, and all Taiwan students filled out this item. The results show that there was no statistic difference between Taiwan students' attitude toward global issues (average response value $=6.99 \pm 0.20$ ) and local issue (average response value $=6.55 \pm 0.22$ ). Similarly, there was no difference among American students (average response value of global issue $=5.91 \pm 0.16 \mathrm{v}$. $\mathrm{s}$. average response value of local issue $=6.09 \pm 0$. 17). However, there was a significant difference between American and Taiwan students' responses to global issue. Taiwan students cared more about the global issue by identifying higher value in the rating scale.

\section{Discussion}

The biodiversity issues are clearly of concern to both American and Taiwan undergraduate students as noted in the result section. The majority of both groups expressed lower level of confidence in the ability of science and technology to solve biodiversity problems and they disagreed that people worry too much about the problem of biodiversity issues. In general, American students expressed stronger attitudes than Taiwan students since they tended to select "strongly disagree" or "strongly agree

With regard to the solution of biodiversity attribute to the personal level, American students were confident that they could make contributions to solve problems, but less students were willing to make personal sacrifices to this end. The relative unwillingness mirrors findings from previous studies, one is a study of secondary students' attitude towards solving environmental problems[21] and the other is study of undergraduate students' engagement in environmental behavior[22].

Comparing to American students, less Taiwan students were confident that they could make a significant contribution to solve problems. This result coincides with the findings of a study conducted in Taiwan [23]. That study assessed secondary school teachers' perceived ability (i.e. internal locus of control) to influence the solution of a discrete environmental problem by using the prompt "To what extent do you believe that you can influence the solution of an environmental issue by acting on your own?" The results showed that secondary school teachers had a moderate level of internal locus of control despite of positive environmental attitude and high levels of environmental sensitivity. In addition, the low level of confidence shown by Taiwan students in the current study was also relevant to the high proportion of agreement with the statement that the problems should be left to the expert.

There was a substantial level of support among Taiwan students for the notion of the natural world as something sacred and that should be left in peace. They also demonstrated views of pragmatic concerns and supported that exploitation of natural resources for basic human needs must be developed although they disagreed with exploitation of biodiversity for its economic potential. Taiwan students seemed to have conflict attitudes shown by their responses to these statements, and which might influence their confidence of personal contribution and responsibility to the resolution of biodiversity problems. These results showed similarities to those of research in environmental issues as several studies suggested that environmental issues caused people's feelings of overwhelming, worries, ambiguities and contradictions[24, 25].

A small number of students self-reported their experience of conservation works. The experiences of conservation activities seemed to make American students be more concerned about the issues and more confident about their own contribution to solving biodiversity issues instead of leaving the problems to the experts. On the other hand, Taiwan students with conservation experience felt that the problems of biodiversity issues were better left to the experts. Perhaps these students recognized the complexity of solving the biodiversity issues through their participation in the related activities; therefore, they felt that the problems of biodiversity issues were better left to the experts.

It would be rash to assume that when students respond to the statements in the questionnaire, each has precisely the same understanding of biodiversity issues and is thus capable of attaching a common priority to addressing it. We suggest further research to study the factors that determine students' attitudes toward a range of biodiversity issues. Despite the limitation described above, the findings from the study raise important issues for those with a practical or research interest in biodiversity education. There are significantly different views among students of two countries and different background. It is important in any program of biodiversity education to address directly the issues that divide students in their responses to the questionnaire statements, therefore, students can appreciate that there are different ways of thinking about challenges in biodiversity and different ways of responding to them.

The current study helps us gain insight into students' attitudes toward biodiversity. Understanding students' attitudes is important and useful for educators to plan curriculum and instruction. The difference between American and Taiwan students' responses to global issue prompts us to suggest that the biodiversity curriculum should include the discussion of both local and global issues. Many researchers [27] also advocate the development of undergraduate curriculum that supports understanding of global issues and the interdependence of nations. Students 
need to learn inter-connection between biodiversity and socio-economic factors, as well as the effects of human activities on biodiversity at local and global levels. We believe that there is considerable value to engage students in caring local dimension as well as global dimension of biodiversity issues since the current biodiversity crisis is a global problem [6] and requires the cooperation of all nations to help resolve problems.

Biodiversity is an abstract, complex issue, and it is difficult for students to understand and learn such concepts easily [26], we suggest two perspectives to build biodiversity curriculum: "the nature and self" and "the ecological literacy." The "nature and self" perspective encourages opportunities to experience and value biodiversity first-hand. Key ideas to be included are: enjoyment, sense of wonder, appreciation, experience, conservation, caring, etc. The “ecological literacy” perspective seeks to develop ecological literacy by addressing the interdependent relationships that exist between different species and by discussing the impact of human activities on environment. Key ideas to be included are: species, habitat, ecosystems, relationships between species, food webs, nature, human impact, sustainable development, respect for pluralism, etc. An instructional activity (Investigation of endangered species) is created to increase students' protective attitudes toward a particular species. At the first step, students will observe and investigate plants and animals in their immediate environment (i.e. school, home and local community), so they will become knowledgeable about local species. The knowledge and skills of studying locality will be expanded to the understanding of global linkages and interdependence, and the notion of dynamic equilibrium. Secondly, students will take next step to research endangered species about the relationships, ecological principles, and factors influencing habitat loss and creation. They will then select one species to analyze the role of people in affecting the state of biodiversity and recommend for conservation strategies. In the future, upon implementation of the curriculum, students' learning outcomes will be assessed, and the modification of curriculum and in-depth research will be conducted.

The current rate of biodiversity loss necessitates action now. We also suggest the need to empower students for actively taking responsibility on biodiversity issues. Students need to be engaged to deal with controversial issues, take a moral position, raise critical questions, make choices, and develop action competence. A project (Green journal)is designed to help students determine their own pathways to sustainable living and develop action competence to positively impact biodiversity. The classroom instructions discuss issues such as ecological footprint and climate change, so students will gain a better understanding of the way people shape biodiversity both positively and negatively. Students then keep journal of their daily consumption of varied resources such food consumptions, transportation and so on. They also record what changes they will make and the consequence of the

Gender: Male Female change. This project enables students to attach personal meaning to biodiversity by embedding it in a specific context in which they become psychologically and physically involved. It promotes students' willingness and ability to adopt lifestyles that are compatible with the wise use of environmental resources. Researchers have suggested that greater knowledge and stronger attitudes are indicated among people who undertake more frequent environmental activities [28, 29]. Through their own actions of such "green journal" project, students will thus be able to develop a degree of confidence that they can help solve community and global issues and that their actions have an impact on people and places in the community and other parts of the world. Their feelings of overwhelming, worries and ambiguities shown in the study will be lessened. It will then continue the cycle of interest and involvement, and add to the strengthening of pro-biodiversity attitudes, and commitment to sustainable values.

\section{Conclusion}

The United Nations [30] designated 2011-2020 as the United Nations Decade on Biodiversity to support the implementation of the strategic plan for biodiversity and promote its overall vision of living in harmony with nature. We took an initial step to investigate undergraduate students' attitudes towards biodiversity and to compare the attitude between students of two countries. Both American and Taiwan undergraduate students had consensus that they expressed lower level of confidence in the ability of science and technology to solve biodiversity problems, and they did not agree that people worry too much about the problem of biodiversity issue. There were also significant differences between different groups.

Embracing the implications from current study, we are on the way to design curriculum and activities that will enable students to connect with nature through discovery, raise confidence level and increase personal contribution. The curriculum relevance will be seen from the point of view of the students, so students will be able to determine their own pathways to sustainable living based on well-informed and critical decision making. Therefore, they will develop hope and vision for the future, and a degree of confidence that an individual can contribute to effecting change.

\section{Acknowledgement}

This research was partly funded by Research and Creative Activity Grant, California State University Sacramento. Any opinions expressed in this work are those of the authors.

\section{Appendix: Survey Questionnaire}


Major:

List the involvement of environment related activities (if any):

To what extent do you agree with the following statements about problems with the biodiversity issues, check one of the followings that express your opinion the best.

Strongly disagree (SD), Disagree (D), Agree (A), Strongly Agree (SA), No opinion (NO)

1. The goal of conserving biodiversity is a threat to the continued economic prosperity of our country

2. Problems of biodiversity issues should be left to the experts.

3. The demand for economic growth is critical enough to justifying relaxing some of the environmental restrictions relating to biodiversity issues.

4. I think each of us can make a significant contribution to solve problems of biodiversity issues.

5. I am willing to have problems of biodiversity issues solved even if this means sacrificing many goods.

6. Science \& technology can solve all problems of biodiversity issues.

7. The natural world is sacred and should be left in peace.

8. Nearly all human activities cause the loss of biodiversity

9. Exploitation of natural resources for basic human needs must bedeveloped even if it results in the lost of wildness and much smaller wildlife populations.

10. People worry too much about the problem of biodiversity issues.

$\begin{array}{lllll}\text { SD } & \text { D } & \text { A } & \text { SA } & \text { NO } \\ \text { SD } & \text { D } & \text { A } & \text { SA } & \text { NO } \\ \text { SD } & \text { D } & \text { A } & \text { SA } & \text { NO } \\ \text { SD } & \text { D } & \text { A } & \text { SA } & \text { NO } \\ \text { SD } & \text { D } & \text { A } & \text { SA } & \text { NO } \\ \text { SD } & \text { D } & \text { A } & \text { SA } & \text { NO } \\ \text { SD } & \text { D } & \text { A } & \text { SA } & \text { NO } \\ \text { SD } & \text { D } & \text { A } & \text { SA } & \text { NO } \\ \text { SD } & \text { D } & \text { A } & \text { SA } & \text { NO } \\ \text { SD } & \text { D } & \text { A } & \text { SA } & \text { NO }\end{array}$

\section{REFERENCES}

[1] M. Siegel. High school students' decision making about sustainability. Environmental Education Research, 12(2), 201-215, 2006.

[2] Convention on Biological Diversity.http://www.cbd.int/conv ention/articles/default.shtml?a=cbd-02

[3] A.T. Peterson. Predicting the geography of species' invasions via ecological niche modeling. Quarterly Review of Biology, 78, 419-433, 2003.

[4] Beckrich. Global environmental issues. Science Teacher, 78(9), 12-13, 2011.

[5] G. K. Meffe, C. R. Carroll. Principles of conservation biology. Sunderland, MA: Sinauer, 1994.

[6] J. Kenneth, S. Ernest. A role for honors in conservation and biodiversity. Journal of the National Collegiate Honors Council, 12 (2),167-174, 2011.

[7] United Nations. Agenda 21: Programme for action for sustainable development. United Nations Conference on Environmental and Development. New York, NY: United Nations Publications, 1992.

[8] M. Dikmenli.Biology student teachers' conceptual frameworks regarding biodiversity. Education, 130 (3), 479-89, 2010.

[9] D. van Weelie. Contextualizing biodiversity. In O. De Jong, E. R. Savelsbergh \&A. Alblas (Eds), Teaching for Scientific Literature: Context, Competency, and Curriculum, 99-116. Utrecht: CD-Be`ta-Press, 2001.

[10] C. Gayford. Biodiversity education: A teacher's perceptive. Environmental Education Research, 6(4), 347-361, 2000.

[11] E.Sander, P.Jelemenska, U. Kattmann. Towards a better understanding of ecology. Journal of Biological Education, 40, 3, 119-123, 2006.

[12] J. Solomon. Social influences on the construction of pupil's understanding of science. Studies in Science Education, 14, 63-82, 1987.

[13] L.S. Vygotsky. Mind in society: The development of higher psychological processes. Cambridge, MA: Harvard University Press, 1978.

[14] K.Oatley, S. Nundy. Rethinking the role of emotions in education. In D.R. Olson, \& N. Torrance, (Eds). The handbook of education and human development. Blackwell Publishers Ltd, Oxford. p. 257-274, 1996.

[15] J. Dillion, W. Scott. Perspectives on environmental education-related research in science education. International Journal of Science Education, 24 (11), 1111-1254, 2006.

[16] D. Hicks, A. Bord. Learning about global issues. Environmental Education Research, 7, 415-425, 2001.

[17] R. Tytler. A window for a purpose: Developing a framework for describing effective science teaching and learning. Research in Science Education, 33, 273-298, 2003.

[18] R.E. Roth. Environmental Literacy: Its roots, evolution, and directions in the 1990s. ERIC/SMEA Information Reference Center. Columbus, OH, 1992.

[19] E. O. Wilson. The diversity of life.Boston, MA: Harvard University Press, 1992.

[20] D. Van Weelie, A.E.J. Wals. Making biodiversity meaningful through environmental education. International Journal of Science Education, 24 (11), 1143-1156, 2002.

[21] E. W. Jenkins, R. G. Pell. "Me and the environmental challenges": A survey of English secondary school students' attitudes towards the environment. International Journal of Science Education, 28 (7), 765-780, 2006.

[22] Nisiforou, A.G. Charalambides. Assessing undergraduate 
university students' level of knowledge, attitudes and behaviour towards biodiversity: A case study in Cyprus International Journal of Science Education, 34(7),1027-1051, 2012.

[23] S-J. Hsu, R.E. Roth. An assessment of environmental literacy and analysis of predictors of responsible environmental behavior held by secondary teachers in the Hualien area of Taiwan. Environmental Education Research, 4 (3). 229-250, 1998.

[24] F. Bartiaux. Does environmental information overcome practice compartmentalization and change consumers' behaviors? Journal of Cleaner Production, 16, 1170-1180, 2008.

[25] M. Ojala. Confronting macro social worries: Worry about environmental problems and proactive coping among a group of young volunteers. Futures, 39, 729-745, 2007.
[26] Randier, C. Pupils' factual knowledge about vertebrate species. Journal of Baltic Science Education, 7(1), 48-54, 2008.

[27] A. M. Zapalska, E. Wingrove-Haugland, C. LaMonica, E. Rivero. Teaching global issues in an undergraduate program, Universal Journal of Educational Research,1(1), 10-19, 2013.

[28] N. Beaumont. Ecotourism: The contribution of educational nature experiences to environmental knowledge, attitudes and behaviors. Unpublished Ph.D. thesis. Brisbane: Griffith University.1999.

[29] R. Gilbert. Ecotourism and education for sustainability. International Review for Environmental Strategies, 4(1), 75-83, 2003.

[30] United Nations Decade on Biodiversityhttp://www.cbd.int/2 011-2020/ 